\title{
A DETERMINAÇÃO DO REGIME DE BENS DO CASAMENTO À LUZ DO DIREITO INTERNACIONAL PRIVADO BRASILEIRO
}

\author{
Maristela Basso \\ Professora Doutora de Direito Internacional da Faculdade de \\ Direito da Universidade de São Paulo
}

Resumo:

O Direito aplicável na determinação do regime de bens, o critério para sua determinação, a evolução desse material no País são alguns dos itens observados pela Autora, que finaliza falando sobre o princípio da unidade do regime patrimonial e a Lex Rei Sitae, junto às conclusões pessoais.

\begin{abstract}
:
The applicable Right in the determination of the regime of goods, the criterion for your determination, devolution of that material in the Country is some of the items observed by the Author, that concludes talking about the beginning of the unit of the patrimonial regime and the Lex Rei Sitae, close to the personal conclusions.
\end{abstract}

Unitermos: regime de bens de casal; Lex Rei Sitae.

1. O Direito Aplicável na Determinação do Regime de Bens

\subsection{O Critério Para a Determinação do Regime de Bens do Casal}

Em Direito Internacional Privado a categoria "regime de bens do casamento" tem um sentido preciso e, como disse Haroldo Valladão, "abrange apenas o conjunto das disposições que regulam os bens pertencentes aos nubentes na ocasião do casamento ou que vierem a adquirir na constância da sociedade conjugal" 1

Se fizermos um estudo de Direito Comparado, constataremos que o "regime de bens do casamento" é um dos aspectos do Direito de Família que mais se diferencia nos diversos sistemas legislativos, e isso remonta à sua própria história.

1. In "Direito Internacional Privado", 3ª ed., Rio de Janeiro, Freitas Bastos, 1983, v. II, p. 81. 
No começo do século XVI, o art. 220 dos "Costumes de Paris" previa que, na falta de pacto antenupcial, os cônjuges, após o casamento, ficavam sob o regime da comunhão, porém a doutrina dominante entendia que essa comunhão compreendia apenas os bens imóveis situados em território governado pelos "Costumes de Paris" Os bens situadọs fora, ficavam sujeitos ao "costume" da respectiva situação. ${ }^{2}$

Levantou-se, então, a discussão entre dois célebres juristas, cujos ensinamentos se tornaram universais: D'Argentré e Dumoulin.

D'Argentré, distinguindo bens móveis e imóveis, afirmava que, inexistindo pacto antenupcial, os bens imóveis dos cônjuges estariam submetidos ao direito do lugar da situação, e os bens móveis, ao direito vigente no lugar do domicílio conjugal.

Inconveniente era essa diversidade de regimes imposta ao casal preconizada por D'Argentré, razão pela qual Dumoulin, partindo da concepção de que os cônjuges tinham liberdade de escolher o regime de bens, concluiu que, quando não-gozavam dessa faculdade, se deveria presumir que resolveram regulá-lo pelo direito em vigor no lugar do domicílio conjugal.

Historicamente, essas duas posições abriram os debates que se seguiram sobre a "regra de solução de conflitos de leis na determinação do regime de bens do casamento"

Para D'Argentré o direito aplicável na determinação do "regime de bens" na falta de pacto antenupcial, era o "estatuto real" (territorial) ao passo que para Dumoulin não era o "estatuto real" nem o "estatuto pessoal" (nacionalidade ou domicilio), pois a própria vontade das partes é que deveria ter efeito extraterritorial.

Sobre essas diferentes posições, observou Amílcar de Castro que "a solução de Dumoulin tinha sobre a de D'Argentré a vantagem de manter a unidade do regime, mas se assentava em premissa falsa, porque não pode haver contrato tácito ... De tal sorte, as disposições facultativas permitem aos nubentes escolher um entre vários regimes de bens; $e$ se os nubentes não se servem dessa faculdade, a disposição supletiva impõe ao casal determinado regime, haja, ou não, vontade expressa, ou tácita, em contrário" ${ }^{3}$

2. Vide Amilcar de Castro, "Direito Internacional Privado". Rio de Janeiro, Forense, 1956, v. II, pp. 90 e ss.

3. In ob. cit., pp. 91-92. 
Daí por que as disposições legais são de três espécies: imperativas, facultativas e supletivas. No silêncio das partes, essas últimas funcionam sempre como imperativas frente à faculdade a elas conferida de se valer da disposição facultativa.

Modernamente, os doutrinadores também se dividem.

Story optou pela corrente "realista" de D'Argentré e estabeleceu que, existindo pacto antenupcial, dever-se-ia observar o que fosse pactuado, exceção feita aos imóveis em que haveria apenas um direito de ação, e, não existindo convenção, os móveis estariam sujeitos à lei do domicílio conjugal e os imóveis à lei de sua situação. ${ }^{4}$

Savigny, por outro lado, defendia a doutrina do domicílio e adotava a lei do domicílio do marido para o regime de bens como uma universalidade, independentemente do lugar do casamento ou da situação dos bens. ${ }^{5}$

Para Mancini o regime de bens do casamento poderia entrar nas relações de família ou nas obrigações, o que ensejou, por sua vez, inúmeros debates e divergências doutrinárias, entre seus seguidores, afinal resolvidos no primeiro sentido. A idéia central de Mancini, defensor do princípio da nacionalidade, era a de que o direito gira em torno das pessoas, e não das coisas, daí porque o Direito Positivo deve seguir a pessoa. ${ }^{6}$

Na tentativa de equacionar as divergências, a doutrina coletiva, do "Institut de Droit International" estudou o assunto em sua Sessão de Lausanne, de 5 de setembro de 1888, dedicada aos "conflitos de leis em matéria de casamento e divórcio" e concluiu que o "regime de bens do casal abrange todos os bens, móveis e imóveis que são regidos, à falta de convenção nupcial, pela lei do domicilio matrimonial" ou seja, do primeiro estabelecimento dos cônjuges. ${ }^{7}$

Hodiernamente, como observou Irineu Strenger, "não se pode dizer que o problema esteja resolvido definitivamente, pelos juristas e tribunais. Existe grande divergência tanto na doutrina como na jurisprudência. Alguns autores ainda

4. In "Commentaries on the conflict of laws" 1834.

5. In "Sistema di diritto romano attuale" 1849 , v. 8, capítulo referente ao império das regras de Direito sobre as relações jurídicas.

6. Sobre a doutrina de Mancini, assim como de outros doutrinadores modernos, vide de Maristela Basso, "Da aplicação do direito estrangeiro pelo juiz nacional - O Direito Internacional Privado à luz da jurisprudência", São Paulo, Saraiva, 1987, pp. 30-47.

7. Sobre essa Sessão do "Institut". vide comentários de Haroldo Valladão, in ob. cit., v. cit., p. 87. 
sustentam que tudo deve depender da lei do país onde o casamento foi celebrado, outros dão preferência à lei do lugar onde os bens estão situados, e outros, ainda, à lei pessoal, que deve reger as relações de família sob todos os pontos de vista, sem exclusão daquilo que concerne aos interesses patrimoniais dos cônjuges" 8

\subsection{A Evolução da Matéria no Brasil}

O Direito brasileiro nunca contemplou expressamente dispositivo de Direito Internacional Privado para regular, especificamente, as relações pessoais e patrimoniais dos cônjuges, ${ }^{9}$ razão pela qual esse tema sempre ficou submetido à regra geral de Direito de Família.

A antiga Lei de Introdução ao Código Civil brasileiro (vigência 1917), em seu art. 8, determinava a aplicação da lei nacional da pessoa para os assuntos pertinentes aos direitos pessoais e aos direitos de família. Esta era a sua redação: " $A$ lei nacional da pessoa determina a capacidade civil, os direitos de família, as relações pessoais dos cônjuges e o regime dos bens no casamento, sendo licita quanto a este a opção pela lei brasileira"

Consagrou-se, portanto, em 1916-1917, por influência de Mancini, o "principio da nacionalidade"

Contudo, a partir do Decreto-lei n. 4.657, de 4 de setembro de 1942 atual Lei de Introdução ao Código Civil LICC, abandonou-se o "princípio da nacionalidade" e se consagrou o "princípio do domicílio" como regra para todas as questões relativas à pessoa e seus direitos de família, adaptando-se os indivíduos e os casais, social, econômica e juridicamente, ao solo escolhido para viver, conforme se lê do caput do art. 7 :

"A lei do país em que for domiciliada a pessoa determina as regras sobre o começo e o fim da personalidade, o nome, a capacidade e os direitos de família"

8. In "Direito Internacional Privado", $3^{\mathrm{a}}$ ed., São Paulo, LTr, 1996, p. 583.

9. Vide comentários de Oscar Tenório, in "Direito Internacional Privado", $4^{2}$ ed., Rio de Janeiro, Freitas Bastos, 1955, p. 299. 
Da análise desse dispositivo, decorrem duas hipóteses que devem ser consideradas e sobre as quais devemos refletir por alguns instantes:

$1^{\text {a }}$ O regime matrimonial é estabelecido no Brasil para valer no Brasil, mas por qualquer de seus elementos (como, p.ex., o local de alguns bens imóveis do casal) gera efeitos em outra ordem jurídica;

$2^{a}$. O regime é estabelecido no estrangeiro e se pretende, por alguma razão (imaginemos que uma das partes seja brasileira, ou que o casal, ou um deles, possua imóveis no Brasil), que seja válido aqui.

A primeira hipótese, submete-se ao caput do art. $7^{\circ}$ citado acima, e a segunda ao $\S 4^{\circ}$ desse mesmo artigo, que dispõe: "O regime de bens, legal ou convencional, obedece a lei do país em que tiverem os nubentes domicílio, e, se este for diverso, à do primeiro domicílio conjugal"

$\mathrm{O} \S 4^{\circ}$ do art. 70, é claro ao determinar que quando os "nubentes" isto é, os "noivos" antes do casamento estiverem domiciliados em países diversos, regulará o regime de bens, legal ou convencional, a lei do primeiro domicílio conjugal, logo após o matrimônio.

Como regra de atribuição de efeitos a fatos mistos ou multinacionais (que geram efeitos em mais de um país ao mesmo tempo), as disposições do art. $7^{\circ}$ são excelentes, não apenas porque estabelecem a "unidade do patrimônio" como porque, conforme demonstrado pelo professor Henri Bateman, da Universidade de Paris, "a idéia dominante do assunto é a importância da adaptação do casal ao meio jurídico e econômico em que tem de viver" 10

Tem razão Bateman porque, como observou Amílcar de Castro, "convém, no interesse do casal e de terceiros, que o regime legal, em falta de contrato escrito, seja o desse meio" $"$

É verdade que o caput do art. $7^{\circ}$ refere-se à lei do país em que for domiciliada a pessoa como a competente para ditar as regras sobre os direitos pessoais e os direitos de família.

Correto é, portanto, submeter as questões de Direito de Família à lei do domicilio do casal (art. $7^{\circ}$ caput), ou do primeiro domicílio conjugal (art. $7^{\circ} \S 4^{\circ}$ ) se quando a questão for apresentada tiverem domicílios internacionais diversos. Nesse sentido, sustenta Irineu Strenger que "o casamento é, na verdade, uma das

10. Citado por Amilcar de Castro, in ob. cit., p. 93.

11. In ob. cit., p. 93. 
mais importantes instituições sociais. Ele não engendra somente relações pessoais entre os cônjuges, mas, como o seu fim é o de criar a família, faz nascer direitos e deveres que envalvem o presente e o futuro. As leis que regem o casamento e a família formam no seu conjunto um todo orgânico que não pode ser dividido. Desde logo, cada uma das relações que daí derivam não podem ser submetidas a regras legislativas diferentes, considerando-as como fato isolado e não conexo, sem destruir a unidade da concepção, segundo a qual cada legislador provê a organização da família" 12

O regime do patrimônio do casal e, conseqüentemente, da familia, é questão fundamental em todos os sistemas legislativos não apenas da Civil Law e da Common Law. Os legisladores, em todos os ordenamentos jurídicos, regulam esse "regime" de acordo com os princípios de ordem pública interna e internacional, assim como, em especial, em atenção aos princípios que decorrem da condição jurídica da mulher, de sua maior ou menor subordinação ao marido, e da proteção preventiva (maior ou menor) dos direitos de terceiros.

Como se vê, na tarefa de determinar o critério para o "regime de bens do casal" o legislador inspira-se, não apenas em fundamentos jurídicos, mas, sobretudo, em razões históricas, morais, econômicas e políticas. Por isso se explica que no direito muçulmano, p.ex., o sistema tradicional ainda seja o da separação: total e absoluta.

Assim como o Direito brasileiro consagra a regra da imutabilidade do regime, e princípio de ordem pública internacional, reconhecido expressamente no "Código de Direito Internacional Privado Para as América" (ou Código de Bustamante), incorporado ao sistema pátrio pelo Decreto n. 18.871, de 13 de agosto de 1929, que "não se pode celebrar ou modificar contratos nupciais na constância do matrimônio, ou alterar o regime de bens por mudanças de nacionalidade ou de domicilio posterior ao mesmo (art. 188)"

Como se sabe, no Brasil, somente é possivel a modificação do regime convencional dos bens na hipótese prevista no art. $7^{\circ} \S 5^{\circ}$ da LICC: "O estrangeiro casado, que se naturalizar brasileiro, pode, mediante expressa anuência de seu cônjuge, requerer ao juiz, no ato de entrega do decreto de naturalização, se apostile ao mesmo a adoção do regime de comunhão parcial de bens, respeitados os direitos de terceiros e dada esta adoção ao competente registro" (redação determinada pela 
Lei n. 6.515/77, que substituiu a expressão "universal" pela "parcial").

O regime de bens, portanto, é sempre imutável e fica subordinado ao Direito que a regra de conflito brasileira determinar que seja observado, isto é, a lex domiciliii. Nesse sentido estão as decisões dos nossos tribunais, dentre as quais citamos, a título elucidativo, as que seguem:

"O domicilio é o elemento de conexão no Direito Internacional Privado brasileiro, para definir o estatuto pessoal nas relações advindas do casamento" (RJTJRS, 72:478-82);

"Casamento. Regime de bens. Prevalência do estabelecido na lei brasileira. Ato realizado nos Estados Unidos. Instrumento legalizado no Consulado Brasileiro. Primeira residência do casal no Rio de Janeiro. Aplicação do art. $7^{\circ} \S 4^{\circ}$ da LJCC" (RJTJSP. 572:78-80).

2. O Princípio da Unidade do Regime Patrimonial do Casal e a "Lex Rei Sitae"

Essa questão está diretamente relacionada ao valor que se atribui ao princípio da unidade do regime patrimonial em face da lex rei sitae, prevista no art. $8^{\circ}$ da LICC.

Muitos equívocos são cometidos quando, na tentativa de encontrar solução para os casos de Direito Internacional Privado, esses dois princípios são confrontados. Esses equívocos geralmente acontecem porque a tendência do investigador é a de confundir o critério que deve determinar o regime patrimonial do casal (se comunhão universal, parcial ou separação total), submetido à lei do domicílio (art. $7^{\circ}$ da LICC), com a regra prevista no referido art. $8^{\circ}$ da LJCC, que se destina ao Direito das Coisas e não se confunde com os direitos de família, muito menos com o regime de bens do casal. 
Expliquemos isso melhor.

$\mathrm{O}$ art. $8^{\circ}$ da LICC assim dispõe:

"Para qualificar os bens e regular a relação a eles concernentes, aplicar-se-á a lei do país em que estiverem situados"

Vê-se, claramente, que o legislador faz a correta distinção entre "qualificação dos bens" e "relações a eles concernentes" Isto porque, como é sabido, não há relação jurídica entre a pessoa e a coisa. Essa relação é sempre de fato, haja vista que a relação protegida pelo direito é aquela que se estabelece (invariavelmente) entre pessoas. Quando, em Direito, importa o valor de coisa apropriável, se diz que o bem é "objeto" da relação jurídica.

Dessa forma, a regra geral do art. $8^{\circ}$ da LJCC, citado acima, tem em vista os bens ut singuli (individualmente considerados). Em outras palavras, a qualificação dos bens é dada pela lex rei sitae, isto é, pelo direito do lugar onde se encontram situados.

Segundo Haroldo Valladão, o art. $8^{\circ}$ da LJCC "considera os bens 'ut singuli, e não os que compõem uma universalidade, quais o regime de bens do casamento ou a tutela e curatela, regidos pelo art. $7^{\circ}$ da LICC, ou a sucessão, regulada pelo art. 10 da LICC" "E, portanto, a regra limita-se aos bens, objeto do Direito das Coisas, dos direitos reais, 'jura in re', e não abrange, p.ex., as questões sobre capacidade de fato (lei do domicílio, art. $7^{\circ}$ da LICC), nem sobre a forma dos atos ('locus regit actum' nem sobre a substância e os efeitos dos atos, nem o lugar da constituição (art. $9^{\circ}$ da LICC), ainda que tais questões se referem a bens, 'jura ad rem" ${ }^{\prime \prime 13}$

Cabe, assim, à lex rei sitae qualificar (e classificar) os bens em móveis e imóveis, consumíveis e não-consumíveis, fungiveis e não-fungiveis, alienáveis e inalienáveis, principais e acessórios, públicos e privados, etc.

De acordo com o art. $8^{\circ}$ da LICC, além de qualificar os bens, cabe à lex rei sitae regular a relação a eles concernentes, isto é, regular todos os direitos incluídos no Direito das Coisas, como, p.ex., a extinção da propriedade, da posse (os 
direitos reais).

Como afirma Amílcar de Castro "a complexidade do assunto exige a máxima atenção porque 'a respeito de bens, em si mesmos considerados ou como objeto de relações jurídicas, vários direitos podem ser contemplados: o da situação para o 'ius in re'; o do lugar da constituição do contrato para o 'ius ad rem'; o do domicílio para a capacidade das partes; o do lugar do ato para a forma respectiva; o do domicílio do 'de cujos para a sucessão; a do domicilio conjugal para o regime matrimonial" 14

Não é difícil, assim, concluir que o art. $8^{\circ}$ da LICC nada tem a ver com a determinação do regime de bens do casal, e que a lex rei sitae só se aplica à qualificação dos bens que possam estar envolvidos na partilha do patrimônio do casal, em caso de dissolução da sociedade conjugal, bem como regula a relação a eles concernentes.

Dessa forma, não se pode confundir as duas etapas abaixo relacionadas:

$1^{\mathrm{a}} \mathrm{O}$ investigador deve buscar a lei aplicável à determinação do regime de bens do casal, que, por ser tema de Direito de Família, se submete ao art. $7^{\circ}$ da LICC, ou seja, à lei do domicilio do casal;

$2^{\text {a }}$. Uma vez determinada a lei aplicável ao regime de bens do casal, deve o investigador relacionar todo o patrimônio comum do casal, inclusive os bens imóveis que porventura existam e estejam situados no Exterior.

Agindo, assim, corretamente, dar-se-á conta o investigador de que os bens que estão no Exterior (qualificados e regulados pela lei da sua situação lex rei sitae), ainda que relacionados no patrimônio do casal, em ação que tramita no Brasil, somente poderão ser objeto de partilha no foro da respectiva situação, por força do art. 89 do CPC.

Entretanto, não se pode confundir a competência processual do juiz do local da situação do bem imóvel somente para processar a partilha, com a competência do juiz brasileiro de (1) conhecer da ação de dissolução da sociedade conjugal e decidir acerca do regime de bens do casal, o que deve ser feito à luz da lei do domicílio; (2) (re)conhecer, de acordo com o principio da unidade e imutabilidade do regime de bens, a existência, no patrimônio comum do casal, de bens situados no Brasil e no Exterior; (3) mandar relacionar esses bens, 
independentemente do lugar em que estejam; e (4) partilhar o patrimônio comum do casal, tendo presente que da universalidade dos bens aqui devem ser partilhados os imóveis situados no Brasil, pois aqueles situados no Exterior devem ser submetidos ao juiz do país de localização.

Se isso não for feito, uma das partes verá solapado seu direito, qual seja, de ver corretamente arrolado o patrimônio comum do casal.

Vale a pena rever o voto do desembargador Ney Almada:

"Com respaldo doutrinário, cabe salientar que os bens do estrangeiro situados em território brasileiro aqui serão objeto de inventário e partilha. Existente, todavia, em espaço alienígena, este simples fato acarreta a fixação da competência no foro da respectiva situação... Assim, menção dos bens sitos na Espanha deve ser feita no inventário processado no Brasil" (RT, 583: 88-9).

Outra passagem extremamente oportuna faz parte do relatório do desembargador Athos Gusmão Carneiro:

"Prevalência, para o juiz brasileiro, da lei material brasileira. Impende ao juiz brasileiro resguardar, na medida do possível, a eficácia da lei material brasileira; no caso concreto, a prevalência das normas relativas à comunhão universal de bens, postergada no inventário realizado no Uruguai. Direito da autora, anulada a renúncia, a haver seu quinhão nos bens deixados pelo progenitor do ex-marido, considerados tanto os bens tantos os bens situados no Brasil como no Uruguai; pagamento a ser feito com bens situados em nosso país" (RJTJRS, 91:245 e ss.). 


\section{Conclusões}

À primeira vista, as questões de Direito Internacional Privado podem parecer difíceis porque suas soluções dependem de uma técnica com a qual não estamos acostumados no nosso dia a dia forense. Essa técnica depende, basicamente, de três momentos:

$1^{0}$ A qualificação do problema, o que deve ser feito pela matéria jurídica a que pertence a questão. No estudo presente temos um problema de regime de bens, problema qualificado como de Direito de Família;

$2^{\circ}$ Uma vez qualificada a matéria, deve-se buscar a norma de Direito Internacional Privado aplicável (arts. $7^{0} 8^{\circ} 9^{\circ} 10$, etc. da LICC ou outra fonte). No estudo presente, qualificada a matéria como sendo de Direito de Família, aplica-se o art. $7^{\circ}$ da LICC;

$3^{0}$ Localizado o art. $7^{0}$ da LICC, aplica-se o direito material (nacional ou estrangeiro) indicado pela norma.

Aplicando-se essa técnica (ou metodologia de solução), podemos concluir no estudo da determinação do regime matrimonial de bens em Direito Internacional Privado:

$1^{\circ}$ O regime patrimonial de bens, de acordo com o art. $7^{\circ}$ da LICC, é o do domicilio do casal;

$2^{0} \mathrm{O}$ regime de bens do casal está submetido, por razões de ordem pública interna e internacional, ao "princípio da unidade do regime patrimonial" mesmo em face da lex rei sitae";

$3^{0}$ A prevalência para o juizo brasileiro deve ser a de resguardar a eficácia e a aplicação da lei material aplicável (indicada pela norma de conflito) relativa à comunhão universal de bens, considerando tanto os bens imóveis situados no Brasil quanto no Exterior, se houver.

Esses são os critérios de solução à luz do Direito Internacional Privado brasileiro, cujas normas comandam a própria atividade jurisdicional do Estado, porque são normas de natureza cogente - de ordem pública, como lapidarmente observou o desembargador Donato João Sehnen do TJRS: 
"Casamento de estrangeiros. Regime de bens. Direito interespacial. Ordem jurídica aplicável.

As normas de Direito Internacional Privado comandam, em realidade, a própria atividade jurisdicional do Estado. São normas da natureza cogente e enceram um profundo sentido de ordem pública"... "A natureza da lide demonstra, assim, a existência de um interesse público relevante, um direito indisponivel, qual seja a definição da ordem pública aplicável" (RJTJRS, 72 :478:82).

São Paulo, março de 2000. 